\title{
Study on the Therapeutic Effects of Traditional Chinese Medicine on Insulin Resistance in Obese Mice by Modulating Intestinal Function
}

\section{Lirong Ma}

Northwest University

\section{Yongquan Bai}

Northwest University

\section{Wenwen Wang}

Air Force Medical University

\section{Rui Shi}

Northwest University

\section{Furong Wang}

Northwest University

Jun Liu

Northwestern University

Chaoyang Liu

Northwest University

Hui Deng

Northwest University

\section{Qing Xu}

Northwest Unversity

\section{Zhang Wenli}

Northwest University

\section{Chen Guo}

Air Force Medical University

Zifan Lu ( $\square$ luzfliuq@fmmu.edu.cn )

Air Force Medical University

\section{Research}

Keywords: Obesity, Chinese medicine, lipid metabolism, inflammation, intestinal flora, Artemisia capillaris, Astragalus propinquus, Phellodendron amurense, Salvia miltiorrhiza, Poria cocos, Anemarrhena asphodeloides 
Posted Date: December 28th, 2020

DOI: https://doi.org/10.21203/rs.3.rs-132207/v1

License: (c) (i) This work is licensed under a Creative Commons Attribution 4.0 International License. Read Full License 


\section{Abstract}

Background: Obesity, in particular with the excessive visceral fat distribution which accompanied by several alterations at hormonal, inflammatory and endothelial level, was great to the detriment to human health. Although there were many treatments for obesity, most of them fail to had a radical effect or were accompanied with several side effects. Traditional Chinese medicine (TCM) for regulating the intestinal flora, lipids, and inflammation were considered to be effective. Based on previous research, Artemisia capillaris, Astragalus propinquus, Phellodendron amurense, Salvia miltiorrhiza, Poria cocos, and Anemarrhena asphodeloides were eventually selected to form an innovative herbal formula.

Methods: The anti-inflammatory and lipid-lowering effects of the TCM were evaluated in an obese mouse models fed with a high-fat diet, and the effects of the TCM on the intestinal flora were further investigated.

Results: The weights and insulin resistant of mice, as well as the inflammation, decreased after treatment. At the same time, the lipid metabolism increased after the mice were gavage with the TCM formula for 2 weeks. The intestinal motility of mice in the drug administration group was enhanced, and the intestinal flora was partially restored.

Conclusion: In summary, our innovative Chinese herbal formula could significantly reduce the weight of obese mice, reduce the intestinal inflammation, improve intestinal motility, and improve the lipid metabolism in mice. Furthermore, the innovative formular could effectively prevent relevant metastasis diseases induced by obesity in mice.

\section{Background}

Obesity has become an epidemic, more than 2 billion people worldwide were overweight or obese, and the World Health Organization estimates that about 300 million people will be obese by 2035 , Therefore, it was very important to develop drugs to treat this life-threatening pandemic [1] .Obesity refers to excess fat relative to height, characterized by increased mass of adipose tissue and dysfunction, leading to systemic lipid extravasation and low-grade inflammation, which would lead to other diseases, such as type 2 diabetes (T2DM) and cardiovascular disease[2]. At the same time, there were significant differences in the structure of intestinal flora between obese patients and healthy people, which may lead to changes in intestinal peristaltic function and intestinal barrier function [3]. Traditional treatments for obesity, weight loss and / or improvement of disordered blood glucose control, it mainly involves weight loss surgery and drugs, but surgery was often highly invasive, irreversible in most cases, not without risk, and most importantly, it was unrealistic as an overall strategy to deal with the global "diabetes" pandemic, at the same time, when most weight loss drugs were used as single hormone therapy, their efficacy and safety were not satisfactory [4]. Therefore, we urgently need new and effective treatments with fewer side effects to solve overweight and improve blood glucose control. 
There were many reasons for obesity, one of which was appetite. Appetite inhibition was a very effective way to treat obesity [5]. Intestinal hormones secreted by intestinal endocrine cells such as CCK, GLP-1 and peptide yy, had a regulatory effect on appetite, it has been found that combinations of gut-derived peptides (cholecystokinin (CCK), glucagon-like peptide-1 (GLP-1), peptide YY (PYY).) would reduce food intake and body weight in rodents [6]. Both CCK and GLP-1 had been confirmed to be satiety signal hormones, CCK and GLP-1 would activate the CCK receptor (CCK1R) and GLP-1 receptor (GLP-1R) of the intestinal vagus nerve to stimulate the vagus nerve and inhibit appetite. In addition, CCK may travel directly from the blood circulation to the center of the brain and directly act on the CCK-1 receptor in nucleus tractus solitarii (NTS) and six different wereas of the hypothalamus to inhibit eating $[7,8]$. Peptide YY may activate proopiomelanocortin (POMC) and inhibit neuropeptide Y (NPY) neurons through hormone pathway, resulting in a sense of satiety and thus reducing food intake [9]. In addition to upregulating saturated signal hormones to treat obesity, down-regulating food-promoting signals was direction to worth to be thinking, gastrin was the only orexin with peripheral activity, which would enter the brain with blood circulation and enter the hypothalamus through vagus nerve and ucleus of solitary tract (TNS), affecting the center of energy regulation and causing an increase in food intake [10,11]. Increased food intake would lead to obesity, which may lead to insulin resistance in the target tissue [12]. Insulin resistance refers to the pathological state in which insulin promotes glucose uptake and decreased utilization efficiency caused by a variety of reasons, as the main glucose uptake tissue: skeletal muscle and fat play an important role in insulin resistance [13]. Insulin would stimulate AKT (protein kinase B) phosphorylation, phosphorylation-AKT lead to glucose uptake, when insulin resistance occurs, the phosphorylation of AKT was inhibited, the glucose uptake of each target tissue was significantly weakened, and the blood glucose concentration will be maintained at a high level $[14,15]$.

Gut was an important organ in human body, in addition to digestion-absorption capacity, it had a barrier function to protect the body [16]. There were a large number of bacteria in human intestinal tract, which form a microbial defense line, namely microbial barrier, by competing with pathogenic bacteria for colonization sites and nutrients, or secreting bacteriostatic substances to inhibit the growth of pathogenic bacteria, in addition to the barrier function, normal flora has been pointed out to play an important role in lipid metabolism. Regulating intestinal flora was a new therapeutic strategy for the control of metabolic syndrome such as obesity, diabetes and non-alcoholic fat disease [17]. Mechanical barrier was the most important structure in intestinal mucosal barrier, and the most important structural basis for its function was the tight junction between intestinal mucosal epithelial cells. Tight junctions of intestinal mucosal

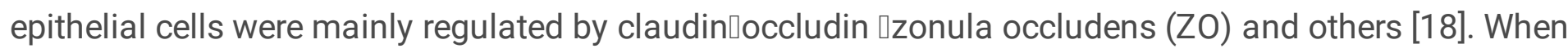
obesity was caused by a high-fat diet, the expression of occludin and Zonula occludens proteins was inhibited, and the intestinal barrier function was impaired [19]. As the largest mucosa-associated lymphoid tissue in the whole body, the intestinal tract has a strong immune function, and there were a large number of immune cells in the intestinal tissue, which provide good protection for the intestinal tract [20]. However, under the condition of long-term high-fat diet, inflammation would occur in the distal small intestine and colon, and the expression of pro-inflammatory genes such as IL-6 and TNF-a would be increased, while the expression of anti-inflammatory genes such as IL-10 and IL-7a would be 
decreased. These inflammatory reactions were not conducive to the stability of intestinal barrier [21]. Beside intestinal inflammation, obesity would also induce systemic chronic low-grade inflammation, which was mainly manifested as increased pro-inflammatory concentration in the blood and decreased anti-inflammatory factor concentration [22]. Meanwhile, obesity would cause oxidative stress in the intestinal tract and decrease the expression of antioxidant genes such as SOD, resulting in intestinal damage [23].

In addition to the impairment of intestinal barrier function, intestinal motor function was also impaired in obese mice [24]. 5-hydroxytryptamine (5-HT) was an important part of the brain-gut axis regulation pathway and plays an important role in maintaining normal gastrointestinal function [25]. $90 \%$ of $5-\mathrm{HT}$ in the body was synthesized, secreted, and activated by enterochromaffin cell (EC) in the gut; tryptophan hydroxylase (TPH) acts on tryptophan to produce 5-hydroxytryptophan, which was then formed in response to 5-hydroxytryptophan decarboxylase; 5-HT mainly functions with receptors of 5-HT1, 5-HT2, 5HT3, 5-HT4 and 5-HT7 in the intestinal tract to regulate gastrointestinal motor function; The -HT2 receptor mainly exists in the peripheral tissues such as the digestive tract. When stimulated by $5-\mathrm{TH}$, it would cause the smooth muscle contraction of the gastrointestinal tract and promote the intestinal movement [26].

As a chronic systemic metabolic disease, obesity was difficult to achieve the desired therapeutic effect from single phenotypic therapy [4]. Traditional Chinese medicine (TCM) has a good effect in the treatment of metabolic diseases [27]. It was reported that many Chinese medicine monomers would also regulate intestinal flora in animal models, such as Poria cocos and Salvia miltiorrhiza polysaccharides would improve hyperglycemia and hyperlipidemia by regulating intestinal microorganisms $[28,29]$. Cortex phellodendri extract would significantly improve the intestinal flora of mice and increase the serum GLP-1 content of mice [30]. In addition, light body powder, seaweed light body soup, lotus leaf ash prescription and other Traditional Chinese medicines also had a good effect on weight loss [27]. However, most of the effects of these formulas were mainly focused on clearing heat and dehumidifying, removing stagnation and stopping diarrhea. At present, there was no good therapeutic effect on metabolic dysfunction caused by obesity, intestinal peristalsis and systemic inflammation. In the ancient book "Medical Jin Jian" of traditional Chinese medicine, there was a kind of medicine called Zhibai Dihuang Pill, which was mainly used to treat Yin deficiency. Modern pharmacological studies had found its pharmacological effects, and it has been reported to reduce blood glucose levels and anti-tumor effects [31]. However, there were too many Chinese herbs in this prescription and no further research has been done. This study selected artemisia hairy Stem, astragalus, Phellodendron, Salvia miltiorrhiza, poria cocos, anemarrhena, and other traditional Chinese medicines to study their impact on obesity. Early reports suggest that these herbs would curb obesity. Through a large number of experiments, we determined the dose of the drug. This formula was an improvement and innovation of the traditional formula, and was expected to had a therapeutic effect on insulin resistance in obese individuals through the intestinal tract. In this study, we determined the new formula through a large number of pre-experiments. Taking high-fat mice as the obesity model, the mice in the experimental group and the control group were intragastric treated, and the model was successfully established through the statistical analysis of mouse weight monitoring, adipose 
histopathological examination, glucose tolerance and insulin tolerance. Through $16 \mathrm{~S}$ sequencing of microbial flora, serological detection and related protein detection of intestinal samples, we confirmed that this TCM formula would alleviate obesity by regulating lipid metabolism and affecting intestinal microenvironment flora of mice.

\section{Method}

\section{Materials}

Primary anti-P-Akt and AKT antibodies were purchased from Signalway Antibody (USA), ZO-1 and Occludin (02902) antibodies were purchased from ProteinTech (USA). The Biotinylated Goat Secondary Antibody (G23303) was purchased from Servicebio (Wuhan, China). Beta-actin (\#8457) weas purchased from Cell Signaling Technology (Cambridge, MA, USA). The mouse GLP-1 ELISA Kit and 5-HT ELISA Kit were purchased from cloud-clone (Wuhan, China). The mouse IL-6 ELISA kit and IL-10 ELISA kit were purchased from Dakewe Biotech Co. The CFX96 real-time PCR instrument was from Bio-Rad (USA), and the Powerlab 8/35 data acquisition and analysis system were from AD Instruments (Australian).

\section{Extraction of herbal components}

Dried Artemisia capillaris, Astragalus propinquus, Phellodendron chinense, Salvia miltiorrhiza, Poria cocos, and Anemarrhena asphodeloides (Shengsheng Traditional Chinese medicine Yinpian, Shaanxi) were extracted individually under reflux using deionized water for $1 \mathrm{~h}$ and the extraction were repeated once. The extracts were filtered, centrifuged to remove undissolved particles and freeze-dried into powder. The extracts were mixed in a certain proportion and dissolved in normal saline and stored at $4^{\circ} \mathrm{C}$.

\section{Animals and animal treatment}

Male C57 mice (4 - 6weeks old) were purchased from the Experimental Animal Center of the Fourth Military Medical University and housed in cages under controlled temperature $\left(24 \pm 2{ }^{\circ} \mathrm{C}\right)$ and $12 \mathrm{~h}$ light/12 $\mathrm{h}$ dark cycles with free access to water and chow. All animal procedures were approved by the Laboratory Animal Center and Animal Care and Welfare Ethics Committee of the Fourth Military Medical University.

Mice were randomly divided into the blank control group, the high-fat control group and the high-fat drug group $\left(26 \mathrm{~g} / \mathrm{kg}\right.$ per day, $13 \mathrm{~g} \cdot \mathrm{kg}^{-1}$-day ${ }^{-1}$ and $6.5 \mathrm{~g} \cdot \mathrm{kg}^{-1}$-day $\left.{ }^{-1}\right)(\mathrm{n}=10)$. The blank control group was given normal diet and the high fat control group were given high-fat diet (Research Diets, USA). After 8 weeks, $6.5 \mathrm{~g} / \mathrm{kg}, 13 \mathrm{~g} / \mathrm{kg}$ and $26 \mathrm{~g} / \mathrm{kg}$ herbal extracts were given daily by gavage to the high-fat drug group while the high-fat control group was given normal saline. Dietary patterns remained the same during that time. In the early experiments, it was found that there was no significant difference between the high-dose group and the middle-dose group, while the therapeutic effect of the low-dose group was relatively weak. Therefore, after comprehensive consideration, we finally selected the middle-dose group $(13 \mathrm{~g} / \mathrm{kg})$ for subsequent experiments. 
After 12 weeks of the dietary treatments, mice were euthanized by cervical dislocation. Orbital blood was collected, and plasma was obtained by centrifugation at 3,000 rpm/min for $10 \mathrm{~min}$ at room temperature. The intestine was dissected, measured, divided into its different portions (large intestine, small intestine and colon). The liver and fat were also harvested. Tissues were rinsed with PBS containing protease inhibitors, frozen in liquid nitrogen, and then stored at $-80^{\circ} \mathrm{C}$ until further analysis.

\section{Small intestine motor function experiment}

This experiment studied the improvement effect of the drug on small intestine motor ability of mice. The contractility of the small intestine of mice under the same pressure and different drugs was measured by Power Lab polysomnography. Acetylcholine (ACH, Sigma, USA) excites the gut, whereas atropine (Sigma, USA) would inhibit this effect. By the ability of the gut to respond to $\mathrm{ACH}$ and atropine we assessed the motor function of the gut. The small intestine was cut into several pieces, put in good physiological salt buffer. Selected the intestinal segment with the best spontaneous peristalsis, fixed it on the pressure sensor, gave $0.5 \mathrm{~g}$ pressure, let the intestine adapt to the buffer for a period of time, then added $10^{-3} \mathrm{mM}$ atropine into the buffer, then recorded the maximum contraction of the mouse intestine and then replaced the buffer. When intestine movements were stable, added the $10^{-4} \mathrm{mM} \mathrm{ACH}$ into buffer, and waited for the waveform to stabilize, determined the maximum diastolic value of the mouse intestine, and changed to a new buffer to continue the next group of experiments.

\section{Fecal microbiome transplantation (FMT)}

To eliminate as much bacteria in the gut of SPF mice as possible, penicillin (Sigma-Aldrich, $2000 \mathrm{U} / \mathrm{ml}$ ) and streptomycin (Sigma-Aldrich, $2 \mathrm{mg} / \mathrm{ml}$ ), which were typical spectrum antibiotics, dissolved in sterile distilled water in the final concentrations described. The mixed solution weas administered to mice (500 $\mu l$ per mouse) by oral gavage lasted for 3 days. Feces were collected from formula-treated mice under high fat diet and stored at $-80^{\circ} \mathrm{C}$ until use. The feces were dissolved in $1.5 \mathrm{ml}$ PBS homogenized, and then filtered through a 100- $\mu \mathrm{m}$ nylon mesh strainer. The filtered contents were resuspended with PBS in a total volume of $2 \mathrm{ml}$, which $200 \mu \mathrm{l}$ per mouse was administered to obesity mice by oral gavage.

\section{Glucose tolerance tests in mice}

The mice that had to be treated began fasting the day before and could not stop drinking water. After 16 hours, each mouse in each group was marked, removed from the cage, and the fasting blood glucose was measured with a glycemeter (Sigma, USA). The measured value was taken as the blood glucose value at $0 \mathrm{~min}$. These steps were performed as carefully as possible to prevent the mice from excessive fright. After the mice were undisturbed for 30 minutes, the weight was determined, and glucose was injected intraperitoneally at $0.01 \mathrm{ml} / \mathrm{g}$ and the timing were started. Blood samples were taken at 15,30 , 60, 90 and 120 minutes to detect blood glucose levels. At the end of the experiment, feed was added to each cage and the experimental results were analyzed by software.

\section{Insulin tolerance tests in mice}


After the mice had fasted for 4 hours, each mouse in each group was marked, removed from: the cage and the fasting blood glucose was measured with a glycemeter. The measured value was taken as the blood glucose at $0 \mathrm{~min}$. After the mice were undisturbed for $30 \mathrm{~min}$, the weight was determined and the mice were intraperitoneally injected with insulin at a dose of $0.01 \mathrm{ml} / \mathrm{g}$. The timing was started. The blood glucose of each mouse was measured at 15, 30, 45 and $60 \mathrm{~min}$.

\section{Quantitative PCR}

For quantitative PCR analysis, mice tissues were homogenized respectively and RNA was extracted using the Trizol Reagent (Tiangen Biotech, China) according to the manufacturer's protocol. Briefly, $40 \mathrm{mg}$ colonic tissues of each sample added $1 \mathrm{~mL}$ Trizol Reagent. In order to fully homogenize, the colon tissue was homogenized in a mechanical homogenizer until no large tissue mass was observed. Lithium chloride method was used to remove all polysaccharides including residual DSS contaminants. cDNA was synthesized with Reverse Transcriptase kits (Takara, Japan). Real-time PCR was performed using SYBR Green (Vazyme, China), and data were acquired in the ABI fluorescence quantitative PCR apparatus (7500, USA) and analyzed using the comparative Ct method. The primers were listed in Table 1. Targetgene transcription of each sample was normalized to the respective levels of $\beta$-actin.

\section{Western blot analysis}

A 1-cm section of colon tissue was immediately frozen in liquid nitrogen and stored at $-80^{\circ} \mathrm{C}$ before homogenization in cell extraction buffer (Thermo-Fisher Scientific, NSW, Australia) supplemented with 1 mM Phenylmethanesulfonyl fluoride (PMSF) (Sigma, USA) and protease inhibitor cocktail (Sigma, USA). The total protein was obtained and quantified by a BCA procedure. The wasolated proteins were separated by SDS-PAGE electrophoresis. Transferred onto NC membranes and blocked with $5 \%$ skim milk in Tris buffer saline-Tween 20 (TBST) and washed three times for 5 min each time. Then incubated overnight at $4{ }^{\circ} \mathrm{C}$ with respective antibodies. After washed with TBST three times for $15 \mathrm{~min}$, the membranes were incubated with HRP-conjugated secondary antibodies (1:10000) for $1 \mathrm{~h}$ at room temperature. Then, the membrane was washed in TBST and detected by the ECL chemiluminescence detection system (MIniChemi 610, China).

\section{S rRNA gene amplicon sequencing}

PCR amplification of the bacterial 16S rRNA genes V4-V5 region was performed using the forward primer 515F (5'-GTGCCAGCMGCCGCGGTAA-3') and the reverse primer 907R (5'-

CCGTCAATTCMTTTRAGTTT-3'). Sample-specific 7-bp barcodes were incorporated into the primers for multiplex sequencing. The PCR reactions contained $5 \mu$ of Q 5 reaction buffer ( $5 \times), 5 \mu l$ of Q 5 HighFidelity GC buffer (5x), $0.25 \mu \mathrm{l}$ of Q5 High-Fidelity DNA Polymerase $(5 \mathrm{U} / \mu \mathrm{l}), 2 \mu \mathrm{l}(2.5 \mathrm{mM})$ of dNTPs, $1 \mu \mathrm{l}(10 \mathrm{uM})$ of each primer, $2 \mu \mathrm{l}$ of DNA Template, and $8.75 \mu \mathrm{l}$ of ddH2O. Thermal cycling consisted of an initial denaturation at $98^{\circ} \mathrm{C}$ for $2 \mathrm{~min}$, followed by 25 cycles consisting of denaturation at $98^{\circ} \mathrm{C}$ for $15 \mathrm{~s}$, annealing at $55^{\circ} \mathrm{C}$ for $30 \mathrm{~s}$, and extension at $72{ }^{\circ} \mathrm{C}$ for $30 \mathrm{~s}$, with a final extension of 5 min at $72{ }^{\circ} \mathrm{C}$. PCR amplicons were purified using Agencourt AMPure Beads (Beckman Coulter, Indianapolis, IN) and 
quantified using the PicoGreen dsDNA Assay Kit (Invitrogen, Carlsbad, CA, USA). After the individual quantification step, amplicons were pooled in equal amounts, and paired-end $2 \times 300$ bp sequencing was performed using the IIIlumina MiSeq platform with MiSeq Reagent Kit v3 at Shanghai Personal Biotechnology Co., Ltd (Shanghai, China)

\section{Statistical analysis}

Statistical analysis data were expressed as means \pm SEM. Statistical analysis and significance analysis were performed using one-way ANOVA. Post-mortem testing was performed using GraphPad Prism software version 6.0 (GraphPad Software, USA). P-values $<0.05$ were considered statistically significant.

\section{Results}

\section{TCM formula would relieve obesity symptoms of mice.}

After 21 days of continuous treatment, the weights of mice in the high-fat control group increased, whereas the weight of mice in the high-fat administration group decreased significantly (Fig. 1A). The liver lipid droplets of mice in the administration group also decreased significantly in the control group, and the fat cells also decreased (Fig. 1B). Results of insulin and glucose tolerance tests showed that the Chinese herbal formula could improve insulin resistance induced by the high-fat diet (Fig. 1C). Results of immunoblotting showed that (Fig. 1D) p-Akt expression in muscle and fat of mice given high-fat drug was significantly higher than that of mice given high-fat drug control group $(p<0.05)$.

TCM formula would relieve obesity symptoms of mice. (A) The change of mice weight and weight increment in each group. (B) Mice liver and fat oil red staining. (C) glucose tolerance tests (GTT) and insulin tolerance tests (ITT). (D) Western blot to detect P-AKT of muscle and fat protein levels in mice. The Results were presented as means \pm SEM of 8 animals/treatment. The values having different superscripts were significantly different $(* p<0.05, * * p<0.01, * * * p<0.001$, ns $>0.05$, one - way ANOVA test)

\section{Traditional Chinese medicine would reduce fat by affecting the secretion of gastrointestinal endocrine peptide.}

The drug was found to improve the fat phenotype of mice. Therefore, we quantified the levels of endocrine peptides. The GLP-1 level (Fig. 2A) in the small intestine and colon of mice in the drug group was higher than that in mice of the high-fat control group, However, ghrelin level was not significantly different between the small intestine partial administration group and the high-fat control group, whereas the expression level of colonic partial administration group was lower than that in the high-fat control group (Fig. 2B) Considering that appetite would also affect the obesity of mice, we also detected the secretion of PYY in the small intestine and colon of mice (Fig. 2C), the expression of PYY in the small intestine and colon of the treated group was higher than that of the high fat control group. At the same time, the expression of CCK (Fig. 2D) in the small intestine and colon was consistent with that of PYY. 
Except ghrelin, the transcriptional levels of endocrine peptides in the small intestine and colon were statistically significant among the groups. Finally, we detected the expression level of GLP-1 in the serum of mice (Fig. 2E). The content of GLP-1 in the serum of the treated group was higher than that of the highfat control group $(p<0.05)$. It would be considered that the drug has a certain effect on the secretion of endocrine peptides in mice. The serum level of GLP-1 in mice in the administration group was higher than that in the high-fat control group (Fig. $2 e)(p<0.05)$.

Effect of Chinese medicine prescription on secretion of intestinal endocrine peptide. The expression of GLP-1. (A) RT-PCR to detect GLP-1 mRNA expression of the small intestine and colon of mice in each group. (B) RT-PCR to detect ghrelin mRNA expression of the small intestine and colon of mice in each group. (C) RT-PCR to detect CCK mRNA expression of the small intestine and colon of mice in each group. (D) RT-PCR to detect PYY mRNA expression of the small intestine and colon of mice in each group. (E) ELISA method to detect the mice serum concentrations of GLP-1. The results were expressed as means \pm $\operatorname{SEM}(n=8)$. Values having different superscripts were significantly different $(* p<0.05, * * p<0.01, * * *$ $p<0.001$, ns $>0.05$, one - way ANOVA test)

\section{Traditional Chinese Medicine inhibits intestinal inflammation and enhances intestinal barrier function in mice.}

The inflammation factor (IL-6) of small intestine and colon in the treatment group was lower than that in the high-fat control group (Fig. 3A). At the same time, the anti-inflammatory factor (IL-10) and antioxidant abilities (SOD) of the small intestine and colon in the drug group were higher than those in the high-fat control group (Fig. 3B, Fig. 3C). The results showed that the prescription of traditional Chinese medicine played a certain role in inhibiting intestinal inflammation induced by high-fat diet. Obesity would affect the intestinal barrier function of mice, but after drug treatment, it was found that the intestinal barrier function of obese mice recovered to a certain extent compared with the high fat control group (Fig. 3D). High fat environment would increase inflammation in mice, but after intragastric administration, inflammation factor (IL-6) in mice serum decreased and anti-inflammatory factors (IL-10) increased in varying degrees (Fig. 3E).

Evaluation of inflammation and intestinal barrier function in mice. (A) RT-PCR to detect IL-6 mRNA expression of the small intestine and colon of mice in each group. (B) RT-PCR to detect IL-10 mRNA expression of the small intestine and colon of mice in each group. (C) RT-PCR to detect SOD mRNA expression of the small intestine and colon of mice in each group. (D)Western blot was used to detect and quantify the proteins level of occluding and zo-1 in the small intestine and colon of mice in each group. (E)ELISA method to detect different groups of mice serum IL -6 and IL -10 . The results were expressed as means \pm SEM $(n=8)$. Values having different superscripts were significantly different $(* p<$ $0.05, * * p<0.01, * * * p<0.001, n s>0.05$, one - way ANOVA test)

\section{Traditional Chinese medicine prescription would enhance the intestinal motor function of mice.}


The 5-HT secreted by intestinal EC cells was related to intestinal motility and inflammation, so we detected the expression of $5-\mathrm{HT}$ ligand in the small intestine and colon of mice. It was found that high fat environment decreased the secretion of 5-HT2c in the intestine of mice, and the level of 5-HT2c in the intestine of mice was partially restored after administration (Fig. 4A). The expression of 5-HT in the serum of mice was consistent with the results of the ligand (Fig. 4B). As a rate-limiting enzyme for the synthesis of $5-\mathrm{HT}$, we also detected the secretion of tph in the intestine. The results showed that the highfat environment could increase the secretion of tph1 and decrease the secretion of tph2 in the intestine of mice, and this state could be restored after administration (Fig. 4C, Fig. 4D). Then we took the small intestine of the mice to detect the intestinal motor function, and the intestinal spontaneous peristalsis of obese mice was weaker than that of the drug treatment group. After drug stimulation in vitro, the intestinal contractile and diastolic ability of the drug-treated group was stronger than that of the high-fat control group (Fig. 4E).

Traditional Chinese medicine prescription would enhance the intestinal motor function of mice. (A) RTPCR to detect 5-TH2c mRNA expression of the small intestine and colon of mice in each group. (B) ELISA method to detect different groups of mice serum 5-TH. (C) RT-PCR to detect thp-1 mRNA expression of the small intestine and colon of mice in each group. (D) RT-PCR to detect thp-2 mRNA expression of the small intestine and colon of mice in each group. $(\mathrm{E})$ the diastolic and contractile values of small intestine of mice in each group were determined by Power Lab polysomnograph after Atrop treatment of $10-4 \mathrm{~mm}$ Ach and $10-3 \mathrm{~mm}$ under $0.5 \mathrm{~g}$ pressure. The results were expressed as means \pm SEM $(n=8)$. Values having different superscripts were significantly different $\left({ }^{*} p<0.05, * * p<0.01, * * * p<0.001, n s>0.05\right.$, one - way ANOVA test)

\section{The prescription of TCM affects the distribution of intestinal flora in mice, and then the lipid metabolism in mice.}

Early detection of the intestinal flora ingroups of mice, found that high-fat environment would change the intestinal flora in mice. The drug would alter the microbial environment to that of normal mice in mice (Fig. 5A). Cluster analysis showed increase in the proportion of desulfovibrionaceae in obese mice. This bacterium was associated with obesity [32], whereas traditional Chinese medicine inhibited its proliferation. At the same time, traditional Chinese medicine formula could promote rumen bacteria breeding in obese mice, in order to reduce the rate of mice with constipation [33] (Fig. 5B), Through the flora recovery of obese mice, it was found that the body weight of obese mice in the flora recovery group was partially lower than that in the control group (Fig. 5C), intestinal inflammation decreased to some extent, while anti-inflammatory factors increased in varying degrees, and the expression of intestinal tight junction protein was also partially up-regulated in obese mice (Fig. 5D). Compared with the control group, the expression of intestinal GLP-1 in obese mice was also up-regulated to a certain extent (Fig. 5E).

Effects of drugs on intestinal flora in mice. (A) In lavage for 21 days after the mice feces were collected for $16 \mathrm{~s}$ RNA sequencing. (B) The statistical data of desulfovibrionaceae bacteria and rumen bacteria in the intestines of mice. (C) High-fat feeding mice was treated with dung of TCM group to flora transplants 
and recorded weight for seven days. (D) RT-PCR to detect IL-6, IL-10 and occludin mRNA expression of the small intestine and colon of mice after treated with flora transplants. (E) RT-PCR to detect GLP-1 mRNA expression of the small intestine and colon of mice after treated with flora transplant. The results were expressed as means \pm SEM $(n=8)$. Values having different superscripts were significantly different $(* p<$ $0.05, * * p<0.01, * * * p<0.001, n s>0.05$, one - way ANOVA test).

\section{Within the effective dose of TCM had no toxicity on C57 mice.}

After obtaining the effective dose of TCM, we explored it's toxicity. As the results showed, TCM had no influence on body weight of mice (Fig. 6A). Compare with control, the HE showed that the lungs, the spleens, the hearts, the livers and the kidneys were no focal necrosis, no obvious fibrosis, no destruction of cell structure and no inflammation, there was no obvious difference between the two sets (Fig. 6B).

Within the effective dose of TCM had no toxicity on C57 mice. (A) The changes of mice weight between control group and control + TCM group. (B) HE staining of lung, spleen, heart, liver and kidney in each group. The results were expressed as means $\pm \operatorname{SEM}(n=8)$. Values having different superscripts were significantly different $(* p<0.05, * * p<0.01, * * * p<0.001, n s>0.05$, one - way ANOVA test)

\section{Discussion}

The global prevalence of obesity has been sustainably increased over the past 40 years, from less $1 \%$ in 1975 , to $6 \%-8 \%$ in 2016[34]. Many factors were considered as the reason which induced obesity, such as genetic factors, environmental factors, abnormal endocrine regulation, inflammation and changes in intestinal flora changes [5]. Our study mainly discussed the effect of Chinese medicine on insulin resistance in obese mice study, the effect of TCM on insulin resistance in obese mice was studied. This prescription was an innovation of the traditional Chinese prescription "Zhibai Dihuang Tang", which combines the characteristic drugs in the original prescription to observe the overall effect of the drug in mice.

Several Based on previous studies had suggested that, Artemisia capillaris, a plant belonging to the Asteraceae family, grows wild in Asia. Lots of Numerous studies had reported that the antisteatotic, antioxidant, anti-inflammatory, choleretic, antiviral, antifibrotic, and antitumor functions of Artemisia capillaris. Astragalus propinquus and Phellodendron amurense were wildly used in the treatment of traditional Chinese medicine for treatment of viral and bacterial infections, inflammation, as well as cancer in vitro experiment[30, 35, 36]. In vivo experiments showed that poria cocos and its derivatives had anti-cancer, anti-inflammation, anti-oxidation, anti-virus and other beneficial biological activities, and anemarrhena had anti-cancer, anti-nervous disorder, anti-inflammation, anti-coagulation and other pharmacological activities $[28,29]$. Clinical trials had shown that salvia miltiorrhiza could improve redox homeostasis, inhibit cell apoptosis and inhibit inflammatory response [37]. In the previous experiment, we found that TCM prescriptions not only had an impact on the phenotype of obese mice, but also had a certain impact on the intestinal tract of mice, so we started our study from this point. First, we set three doses, $6.5 \mathrm{~g} / \mathrm{kg}$.day, $13 \mathrm{~g} / \mathrm{kg}$.day and $26 \mathrm{~g} / \mathrm{kg}$.day. However, after intragastric administration, we found 
that the phenotypic effects of low doses on experimental mice were weaker than others. Meanwhile, there was no difference in the overall effect between the large dose and the medium dose. Finally, we chose the medium dose (13 g/kg.day) for our study (Fig.S1). The gut was the main organ in the body responsible for energy intake. It communicates with the brain through hormones and neural pathways. With the intake of food, the intestines secrete a variety of peptides, among which YY peptide (PYY), cholecystokinin (CCK) and glucagon-like peptide - 1 (GLP-1) feed back to the nucleus solitone (NTS) by stimulating the vagus nerve [6-8]. The solitary nucleus was the target of intestinal hormones. These brain regions send messages to the paraventricular nucleus and suprachiasmatic nucleus of the hypothalamus, which were the key regulators of metabolic homeostasis [8]. Paraventricular nucleus can regulate autonomic nerve output, the neuroendocrine hormone and supraventricular nucleus can balance sympathetic and parasympathetic nerve output, so as to synchronize the behavior and physiology of the whole body [7-9]. Therefore, the feedback through the intestinal peptide on the energy metabolism in mice, and the fat in the body can cause an inflammatory response, obesity can cause intestinal barrier damage. Traditional Chinese medicine formula could reverse this damage. Many studies had shown that changes in the body could affect the distribution of intestinal flora, and the redistribution of intestinal flora could affect the distribution of intestinal flora in mice in turn. Therefore, we detected the distribution of intestinal flora in mice at a later stage, and found that traditional Chinese medicine could affect the distribution of intestinal flora in mice. After that, we consider whether the microflora of the mice fed with traditional Chinese medicine prescription and the intestinal flora changed can alleviate some of the damage caused by the high-fat environment. Our results showed that the flora of mice fed with traditional Chinese medicine prescription and intestinal flora recovered had a certain effect on the redistribution of microflora in hyperlipidemic mice, and even decreased the expression of inflammatory factors and affected the phenotype of mice. However, the overall effect was weaker than that of the traditional Chinese medicine group, and we consider that it may be due to the short time of bacteria transplantation. In the course of the experiment, there was still a deficiency that the sample size of $16 \mathrm{~s}$ sequencing of mice was not very large, so we cannot count the flora more accurately. In the later experiment, we will take the clinical application of traditional Chinese medicine prescription and intestinal flora as a starting point, focus on the clinical therapeutic effect of the prescription and the application of enriched dominant microflora as a microbial preparation in the treatment of intestinal diseases.

\section{Conclusion}

This Chinese herbal formula has been illustrated to improve insulin resistance, reduce inflammation, improve intestinal motor function and change the distribution of intestinal flora in obese mice through the intestinal tract. This provides a basis for clinical research on the treatment of constipation or insulin resistance caused by obesity.

\section{Abbreviations}


traditional Chinese medicine: TCM, type 2 diabetes: T2DM, cholecystokinin: CCK, glucagon-like peptide-1: GLP-1, peptide YY: PYY, proopiomelanocortin: POMC, neuropeptide Y: NPY, ucleus of solitary tract: TNS, protein kinase B: AKT, phosphorylation-AKT: p-AKT, zonula occludens: ZO, interleukin-6: IL-6, interleukin10: IL-10, interleukin-7a: IL-7a, Superoxide Dismutase: SOD, 5-hydroxytryptamine: 5-HT, tryptophan hydroxylase: TPH, acetylcholine: ACH, glucose tolerance tests: GTT, insulin tolerance tests: ITT, hematoxylin-eosin staining: HE, nucleus solitone: NTS

\section{Declarations}

\section{Ethics approval and consent to participate:}

Every experiment in this article was performed in accordance with the protocols approved by the Fourth Military Medical University Committee on Animal Care. The ethic approval number is: IACUC-20191206.

\section{Consent for publication:}

All authors gave final approval of version to be published

\section{Availability of data and materials:}

The [DATA TYPE] data used to support the findings of this study are available from the corresponding author upon request.

\section{Conflicts of Interest:}

The authors declare no conflict of interest.

\section{Funding:}

This study was funded by the grants from National Key R\&D Program of China (No. 2017YFC1308600, 2018SWZJLZF and CBSKL2014Z06).

\section{Author Contributions:}

L.Y.M, Y.Q.B, G.C. and Z.F.L. all participated in conducting the study. L.R.M, Y.Q.B, G.C and Z.F.L. designed and performed the majority of the study. W.W.W. and R.S analyzed the data. F.R.W, J. L, C.Y.L, H.D and R.S. drafted the manuscript. Q.X and W.L.Z checked and proofread the manuscript.

\section{Acknowledgements:}

I would like to express my gratitude to all those who have helped me during the writing of this thesis. I gratefully acknowledge the help of my supervisor Professor Z.F.L and G.C. I do appreciate her patience, encouragement, and professional instructions during my thesis writing. Thanks for the platform support provided by the Bio-pharmaceutical Teaching and Research Office of The Air Force Military Medical University. 


\section{References}

1. The World Health Organization. Health Topics / Obesity. Available from: https://www.who.int/healthtopics/obesity. [Cited 11 December 2020].

2. Kos K. Cardiometabolic Morbidity and Mortality with Smoking Cessation, Review of Recommendations for People with Diabetes and Obesity. Curr Diab Rep. 2020;20(12):82.

3. Adalsteinsdottir SA, Magnusdottir OK, Halldorsson TI, Birgisdottir BE. Towards an Individualized Nutrition Treatment: Role of the Gastrointestinal Microbiome in the Interplay Between Diet and Obesity. Curr Obes Rep. 2018;7(4):289-93.

4. Sukhdev S, Bhupender S, Singh KS. Pharmacotherapy \& Surgical Interventions Available for Obesity Management and Importance of Pancreatic Lipase Inhibitory Phytomolecules as Safer Anti-Obesity Therapeutics. Mini Rev Med Chem. 2017;17(4):371-9.

5. Hansen TT, Mead BR, Garcia-Gavilan JF, Korndal SK, Harrold JA, Camacho-Barcia L, et al. was reduction in appetite beneficial for body weight management in the context of overweight and obesity? Yes, according to the SATIN (Satiety Innovation) study. J Nutr Sci. 2019;8:e39.

6. Roth E, Benoit S, Quentin B, Lam B, Will S, Ma M, et al. Behavioural and neurochemical mechanisms underpinning the feeding-suppressive effect of GLP-1/CCK combinatorial therapy. Mol Metab. 2020:101118.

7. Sayegh Al. The role of cholecystokinin receptors in the short-term control of food intake. Prog Mol Biol Transl Sci. 2013;114:277-316.

8. Grill HJ, Hayes MR. The nucleus tractus solitarius: a portal for visceral afferent signal processing, energy status assessment and integration of their combined effects on food intake. Int $\mathrm{J}$ Obes (Lond). 2009;33(Suppl 1):11-5.

9. Batterham RL, Heffron H, Kapoor S, Chivers JE, Chandarana K, Herzog H, et al. Critical role for peptide YY in protein-mediated satiation and body-weight regulation. Cell Metab. 2006;4(3):223-33.

10. Schalla MA, Stengel A. Pharmacological Modulation of Ghrelin to Induce Weight Loss: Successes and Challenges. Curr Diab Rep. 2019;19(10):102.

11. Makris MC, Alexandrou A, Papatsoutsos EG, Malietzis G, Tsilimigras DI, Guerron AD, et al. Ghrelin and Obesity: Identifying Gaps and Dispelling Myths. A Reappraisal. In Vivo. 2017;31(6):1047-50.

12. Miao Z, Alvarez M, Ko A, Bhagat $Y$, Rahmani E, Jew B, et al. The causal effect of obesity on prediabetes and insulin resistance reveals the important role of adipose tissue in insulin resistance. PLoS Genet. 2020;16(9):e1009018.

13. Shen S, Liao Q, Zhang T, Pan R, Lin L. Myricanol modulates skeletal muscle-adipose tissue crosstalk to alleviate high-fat diet-induced obesity and insulin resistance. Br J Pharmacol. 2019;176(20):39834001.

14. Beg M, Abdullah N, Thowfeik FS, Altorki NK, McGraw TE. Distinct AKT phosphorylation states were required for insulin regulated Glut4 and Glut1-mediated glucose uptake. Elife. 2017;6. 
15. Sanchez-Aguilera P, Diaz-Vegas A, Campos C, Quinteros-Waltemath O, Cerda-Kohler H, Barrientos G, et al. Role of ABCA1 on membrane cholesterol content, insulin-dependent AKT phosphorylation and glucose uptake in adult skeletal muscle fibers from mice. Biochim Biophys Acta Mol Cell Biol Lipids. 2018;1863(12):1469-77.

16. Fang S, Zhuo Z, Yu X, Wang H, Feng J. Oral administration of liquid iron preparation containing excess iron induces intestine and liver injury, impairs intestinal barrier function and alters the gut microbiota in rats. J Trace Elem Med Biol. 2018;47:12-20.

17. Wang Y, Sun L, Chen S, Guo S, Yue T, Hou Q, et al. The administration of Escherichia coli Nissle 1917 ameliorates irinotecan-induced intestinal barrier dysfunction and gut microbial dysbiosis in mice. Life Sci. 2019;231:116529.

18. Zhang Z, Shi Y, Cai D, Jin S, Zhu C, Shen Y, et al. Effect of electroacupuncture at ST36 on the intestinal mucosal mechanical barrier and expression of occludin in a rat model of sepsis. Acupunct Med. 2018;36(5):333-8.

19. Cani PD, Bibiloni R, Knauf C, Waget A, Neyrinck AM, Delzenne NM, et al. Changes in gut microbiota control metabolic endotoxemia-induced inflammation in high-fat diet-induced obesity and diabetes in mice. Diabetes. 2008;57(6):1470-81.

20. Garidou L, Pomie C, Klopp P, Waget A, Charpentier J, Aloulou M, et al. The Gut Microbiota Regulates Intestinal CD4 T Cells Expressing RORgammat and Controls Metabolic Disease. Cell Metab. 2015;22(1):100-12.

21. Al-Sadi RM, Ma TY. IL-1 beta causes an increase in intestinal epithelial tight junction permeability. J Immunol. 2007;178(7):4641-9.

22. Ter Horst R, van den Munckhof ICL, Schraa K, Aguirre-Gamboa R, Jaeger M, Smeekens SP, et al. SexSpecific Regulation of Inflammation and Metabolic Syndrome in Obesity. Arterioscler Thromb Vasc Biol. 2020;40(7):1787-800.

23. Araujo TG, Oliveira AG, Vecina JF, Marin RM, Franco ES, Abdalla Saad MJ, et al. Treatment with Parkinsonia aculeata combats insulin resistance-induced oxidative stress through the increase in PPARgamma/CuZn-SOD axis expression in diet-induced obesity mice. Mol Cell Biochem. 2016;419(1-2):93-101.

24. Wan X, Yin J, Chen J. Characteristics of Intestinal Myoelectrical and Motor Activities in Diet-Induced Obese Rats: Obesity and Motility. Dig Dis Sci. 2019;64(6):1478-85.

25. Yu YC, Li J, Zhang M, Pan JC, Yu Y, Zhang JB, et al. Resveratrol Improves Brain-Gut Axis by Regulation of 5-HT-Dependent Signaling in the Rat Model of Irritable Bowel Syndrome. Front Cell Neurosci. 2019;13:30.

26. Coates MD, Tekin I, Vrana KE, Mawe GM. Review article: the many potential roles of intestinal serotonin (5-hydroxytryptamine, 5-HT) signalling in inflammatory bowel disease. Aliment Pharmacol Ther. 2017;46(6):569-80.

27. Li C, Zhang H, Li X. The Mechanism of Traditional Chinese Medicine for the Treatment of Obesity. Diabetes Metab Syndr Obes. 2020;13:3371-81. 
28. Jiang Y, Fan L. The effect of Poria cocos ethanol extract on the intestinal barrier function and intestinal microbiota in mice with breast wouldcer. J Ethnopharmacol. 2020;266:113456.

29. Tan Y, Li Y, Zhou F, Guo J, Wang T, Shi Y, et al. Administration of a mixture of triterpenoids from yeyachun and phenolic acids from danshen ameliorates carbon tetrachloride-induced liver fibrosis in mice by the regulation of intestinal flora. J Pharmacol Sci. 2020;143(3):165-75.

30. Xu B, Yan Y, Huang J, Yin B, Pan Y, Ma L. Cortex Phellodendri extract's anti-diarrhea effect in mice related to its modification of gut microbiota. Biomed Pharmacother. 2020;123:109720.

31. Zhao L, Gao H, Zhao Y, Lin D. Metabonomic analysis of the therapeutic effect of Zhibai Dihuang Pill in treatment of streptozotocin-induced diabetic nephropathy. J Ethnopharmacol. 2012;142(3):64756.

32. Nagata N, Xu L, Kohno S, Ushida Y, Aoki Y, Umeda R, et al. Glucoraphanin Ameliorates Obesity and Insulin Resistance Through Adipose Tissue Browning and Reduction of Metabolic Endotoxemia in Mice. Diabetes. 2017;66(5):1222-36.

33. Liu S, Zheng N, Zhao S, Wang J. Exploring the Diversity of Active Ureolytic Bacteria in the Rumen by Comparison of cDNA and gDNA. Animals (Basel). 2020;10(11).

34. Fox A, Feng W, Asal V. What was driving global obesity trends? Globalization or "modernization"? Global Health. 2019;15(1):32.

35. Jang E, Kim BJ, Lee KT, Inn KS, Lee JH. A Survey of Therapeutic Effects of Artemisia capillaris in Liver Diseases. Evid Based Complement Alternat Med. 2015;2015:728137.

36. Auyeung KK, Han QB, Ko JK. Astragalus membranaceus: A Review of its Protection Against Inflammation and Gastrointestinal wouldcers. Am J Chin Med. 2016;44(1):1-22.

37. Wang Y, Dan Y, Yang D, Hu Y, Zhang L, Zhang C, et al. The genus Anemarrhena Bunge: A review on ethnopharmacology, phytochemistry and pharmacology. J Ethnopharmacol. 2014;153(1):42-60.

\section{Figures}


A

B
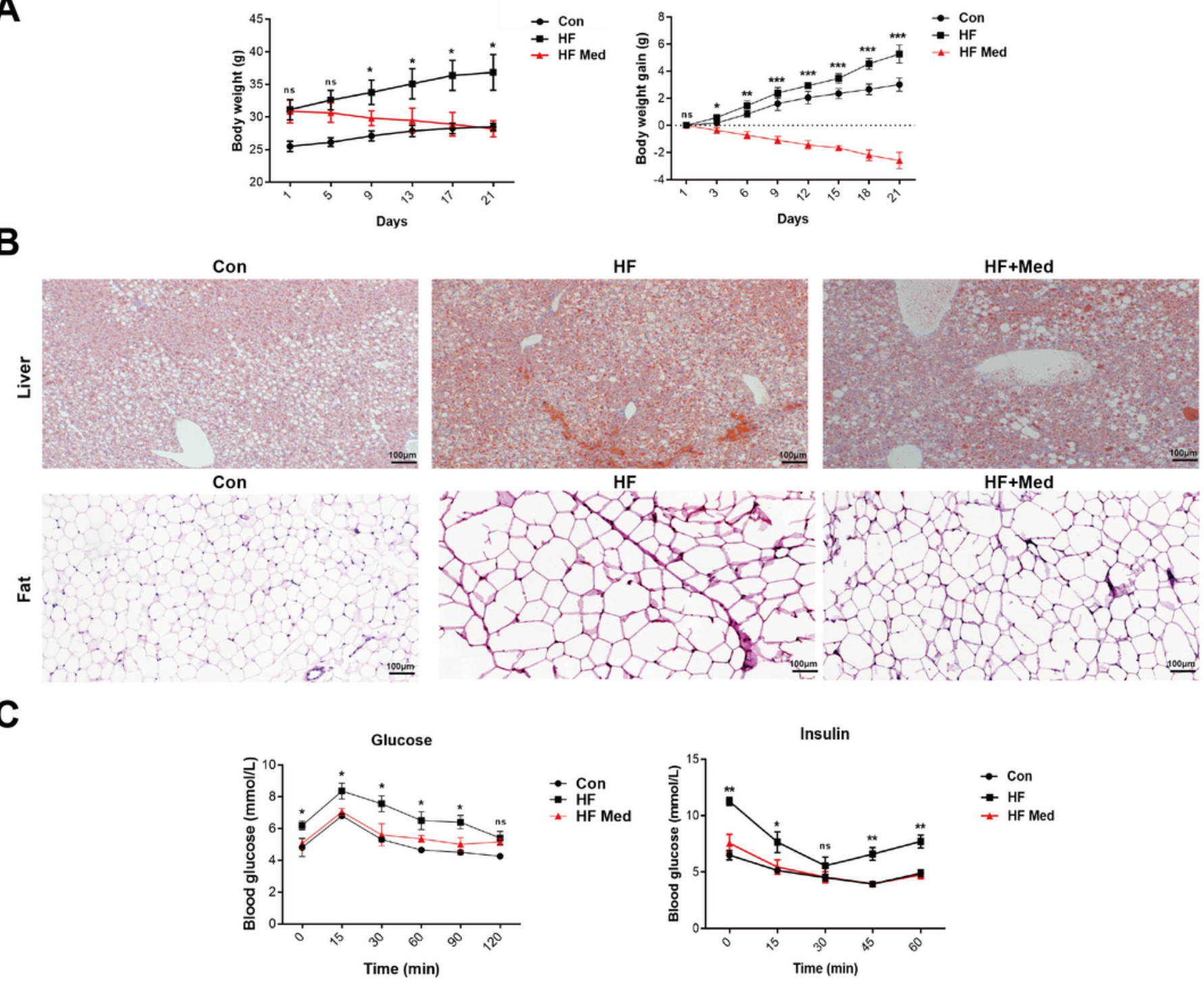

C
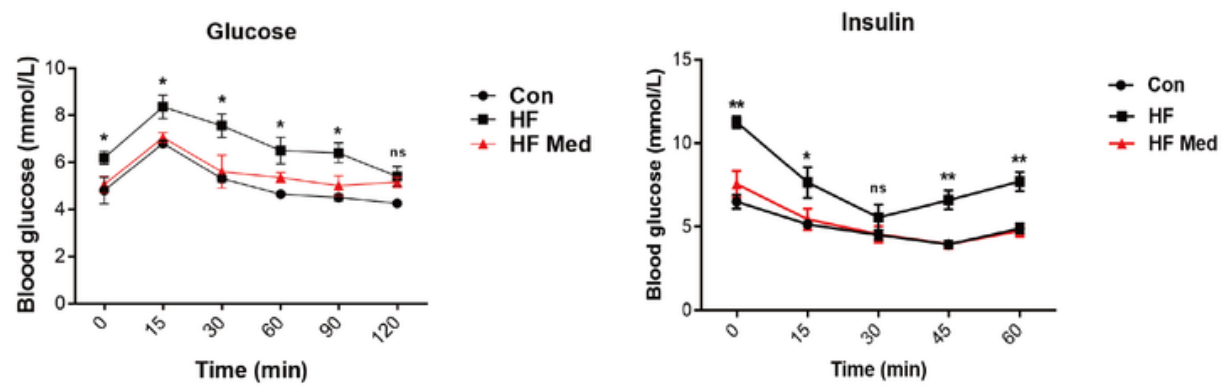

D
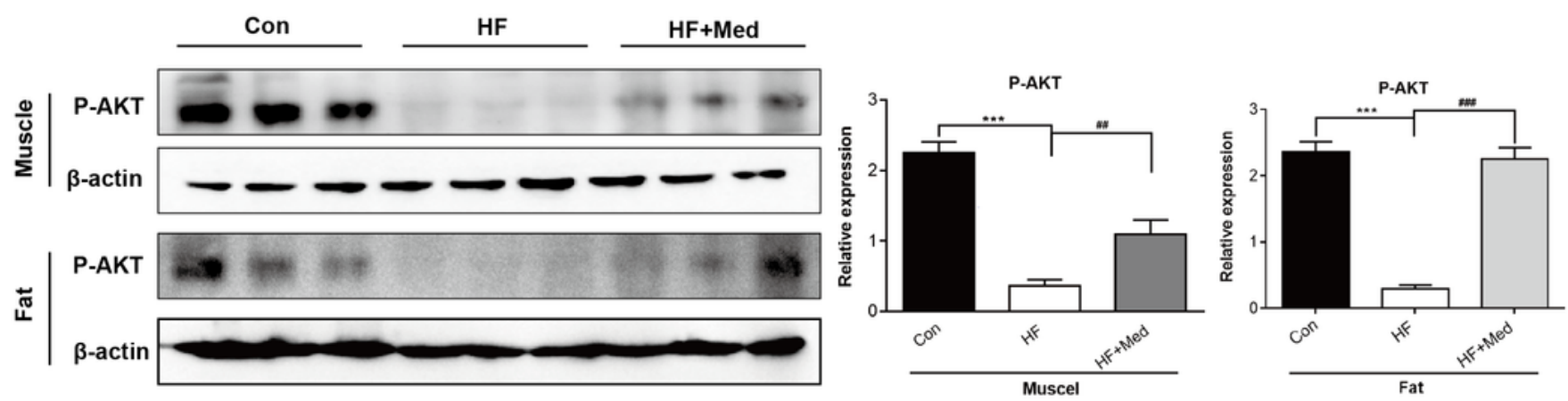

\section{Figure 1}

After 21 days of continuous treatment, the weights of mice in the high-fat control group increased, whereas the weight of mice in the high-fat administration group decreased significantly (Fig. 1A). The liver lipid droplets of mice in the administration group also decreased significantly in the control group, and the fat cells also decreased (Fig. 1B). Results of insulin and glucose tolerance tests showed that the Chinese herbal formula could improve insulin resistance induced by the high-fat diet (Fig. 1C). Results of 
immunoblotting showed that (Fig. 1D) p-Akt expression in muscle and fat of mice given high-fat drug was significantly higher than that of mice given high-fat drug control group $(p<0.05)$.

A

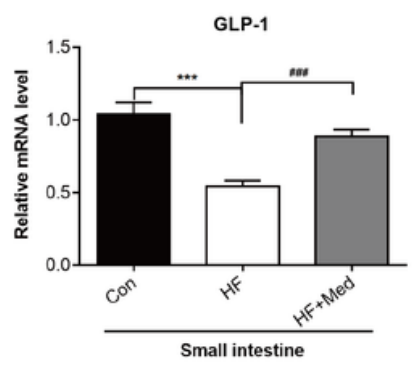

C

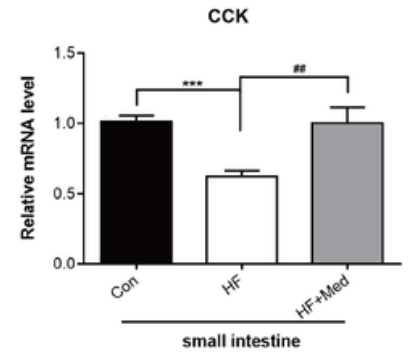

$\mathbf{E}$

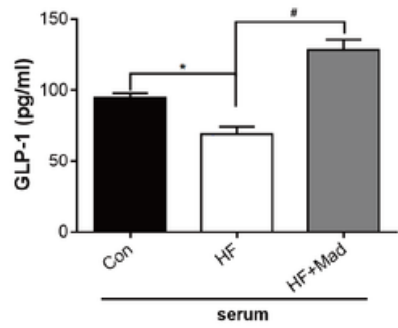

B
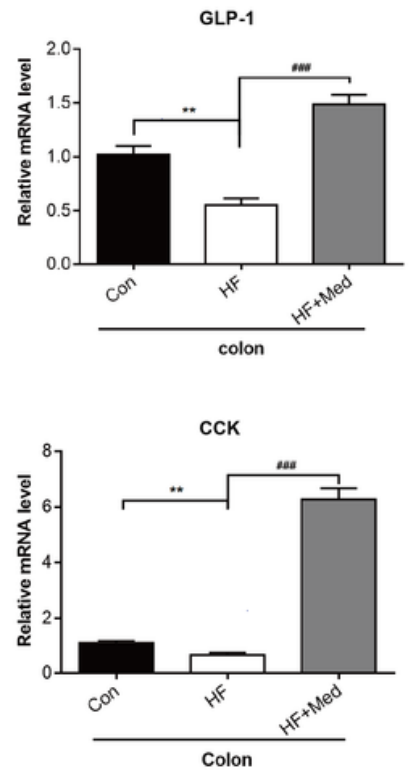

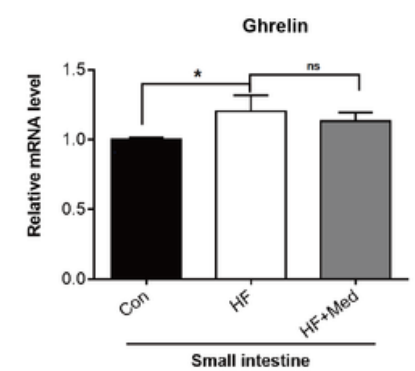

D

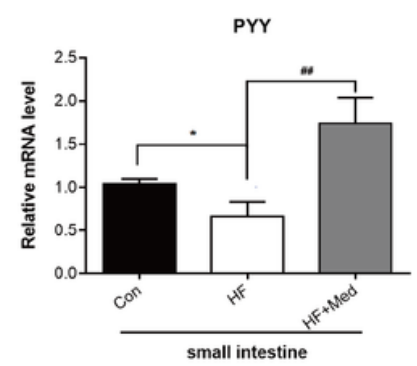

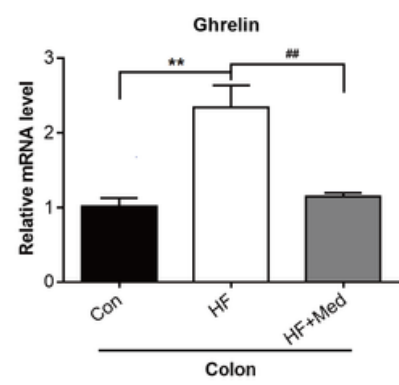

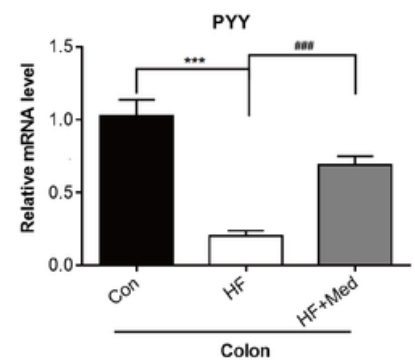

\section{Figure 2}

Therefore, we quantified the levels of endocrine peptides. The GLP-1 level (Fig. 2A) in the small intestine and colon of mice in the drug group was higher than that in mice of the high-fat control group, However, ghrelin level was not significantly different between the small intestine partial administration group and the high-fat control group, whereas the expression level of colonic partial administration group was lower than that in the high-fat control group (Fig. 2B) Considering that appetite would also affect the obesity of mice, we also detected the secretion of PYY in the small intestine and colon of mice (Fig. 2C), the expression of PYY in the small intestine and colon of the treated group was higher than that of the high fat control group. At the same time, the expression of CCK (Fig. 2D) in the small intestine and colon was consistent with that of PYY. Except ghrelin, the transcriptional levels of endocrine peptides in the small intestine and colon were statistically significant among the groups. Finally, we detected the expression level of GLP-1 in the serum of mice (Fig. 2E). The content of GLP-1 in the serum of the treated group was higher than that of the high-fat control group $(p<0.05)$. It would be considered that the drug has a certain effect on the secretion of endocrine peptides in mice. The serum level of GLP-1 in mice in the administration group was higher than that in the high-fat control group (Fig. $2 e)(p<0.05)$. 
A

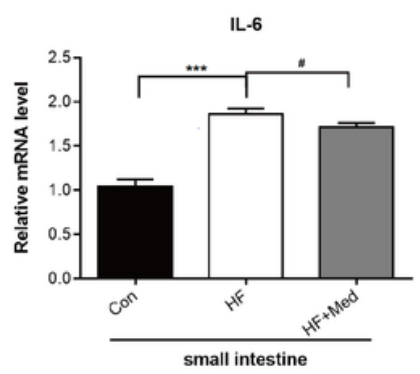

C

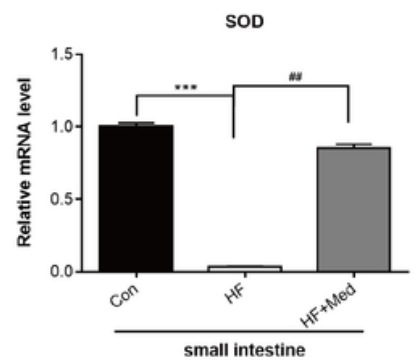

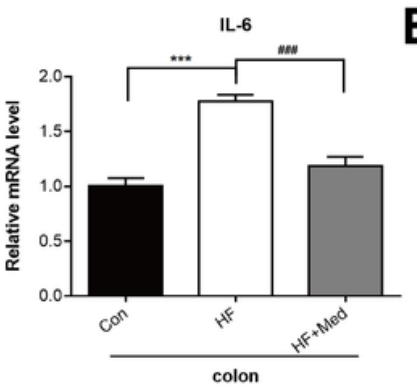

B

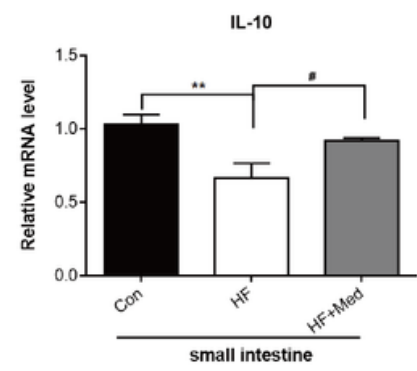

E
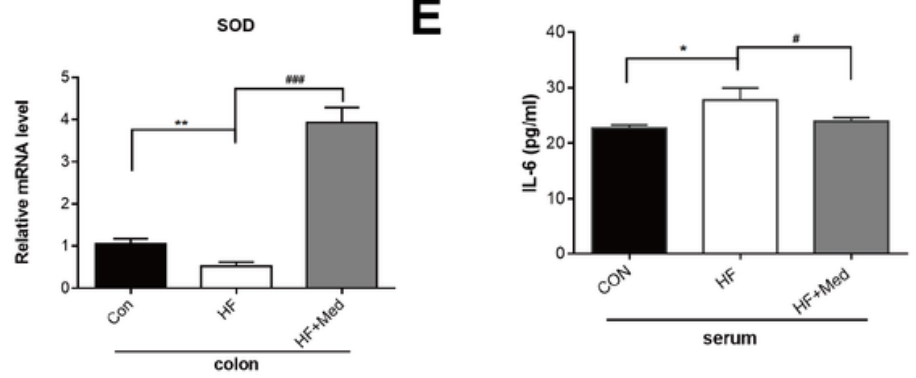
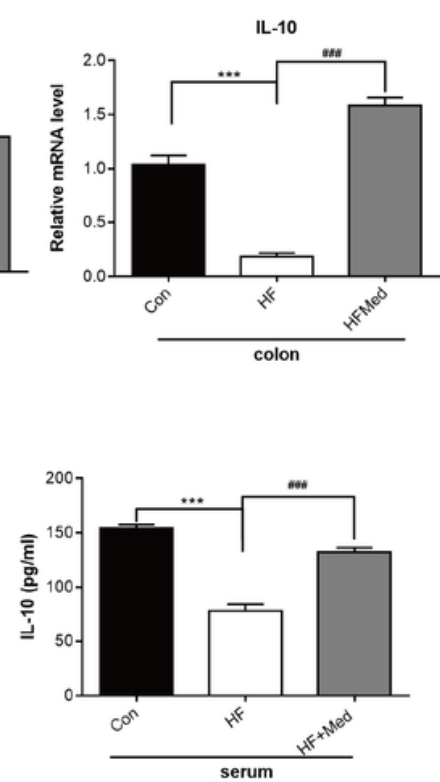

D

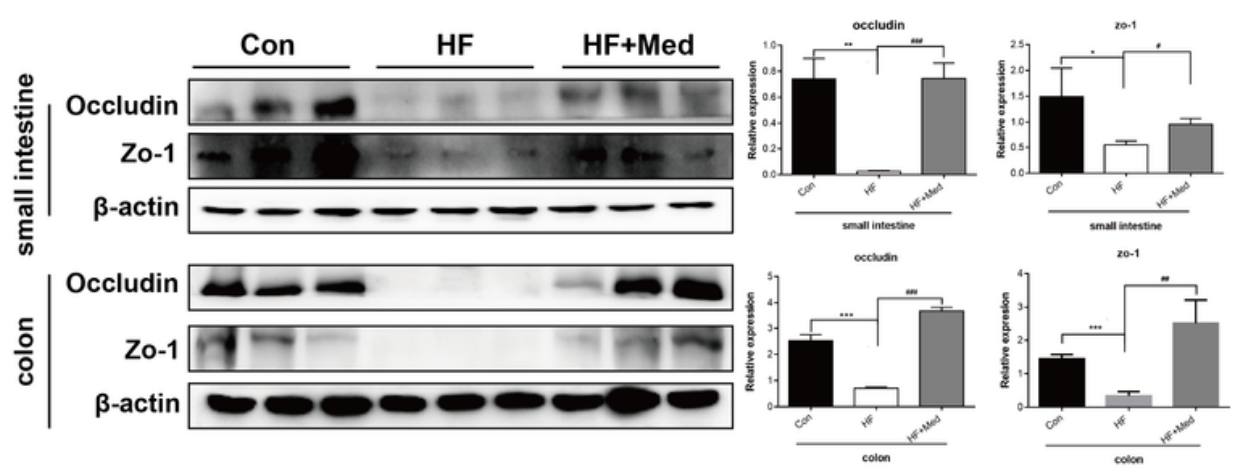

Figure 3

The inflammation factor (IL-6) of small intestine and colon in the treatment group was lower than that in the high-fat control group (Fig. 3A). At the same time, the anti-inflammatory factor (IL-10) and antioxidant abilities (SOD) of the small intestine and colon in the drug group were higher than those in the high-fat control group (Fig. 3B, Fig3C). The results showed that the prescription of traditional Chinese medicine played a certain role in inhibiting intestinal inflammation induced by high-fat diet. Obesity would affect the intestinal barrier function of mice, but after drug treatment, it was found that the intestinal barrier function of obese mice recovered to a certain extent compared with the high fat control group (Fig.3D). High fat environment would increase inflammation in mice, but after intragastric administration, inflammation factor (IL-6) in mice serum decreased and anti-inflammatory factors (IL-10) increased in varying degrees (Fig.3E). 
A

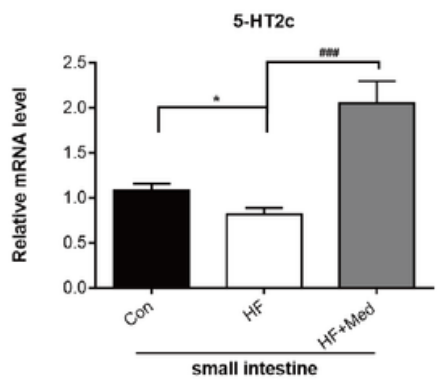

C

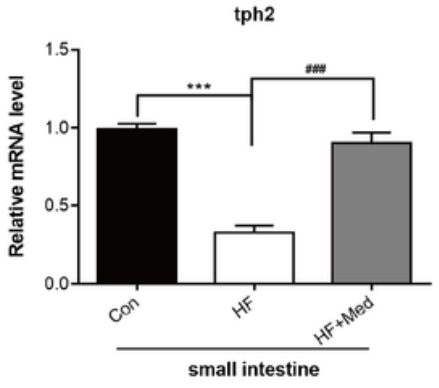

$\mathbf{E}$

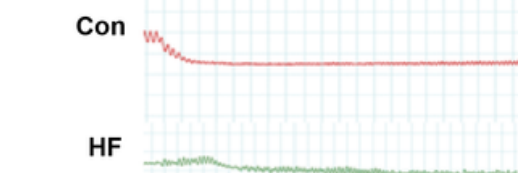

$\mathrm{HF}+\mathrm{Med}$
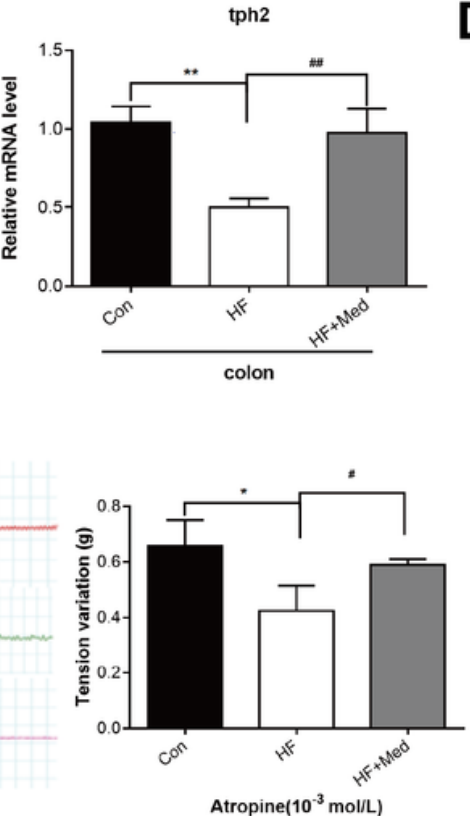

B

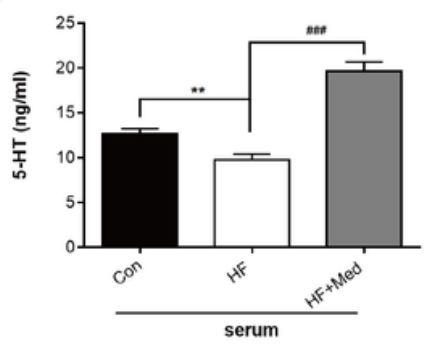

D
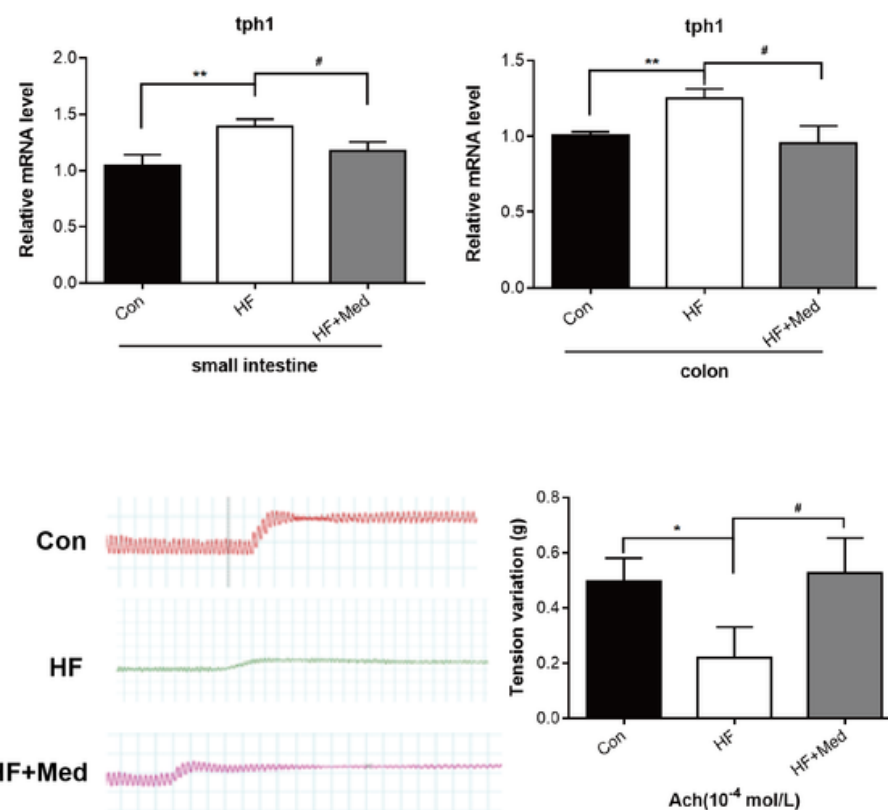

Figure 4

It was found that high fat environment decreased the secretion of $5-\mathrm{HT} 2 \mathrm{c}$ in the intestine of mice, and the level of 5-HT2c in the intestine of mice was partially restored after administration (Fig. 4A). The expression of $5-\mathrm{HT}$ in the serum of mice was consistent with the results of the ligand (Fig. 4B). As a ratelimiting enzyme for the synthesis of $5-\mathrm{HT}$, we also detected the secretion of tph in the intestine. The results showed that the high-fat environment could increase the secretion of tph1 and decrease the secretion of tph2 in the intestine of mice, and this state could be restored after administration (Fig. 4C, Fig4D). Then we took the small intestine of the mice to detect the intestinal motor function, and the intestinal spontaneous peristalsis of obese mice was weaker than that of the drug treatment group. After drug stimulation in vitro, the intestinal contractile and diastolic ability of the drug-treated group was stronger than that of the high-fat control group (Fig. 4E). 


\section{A}
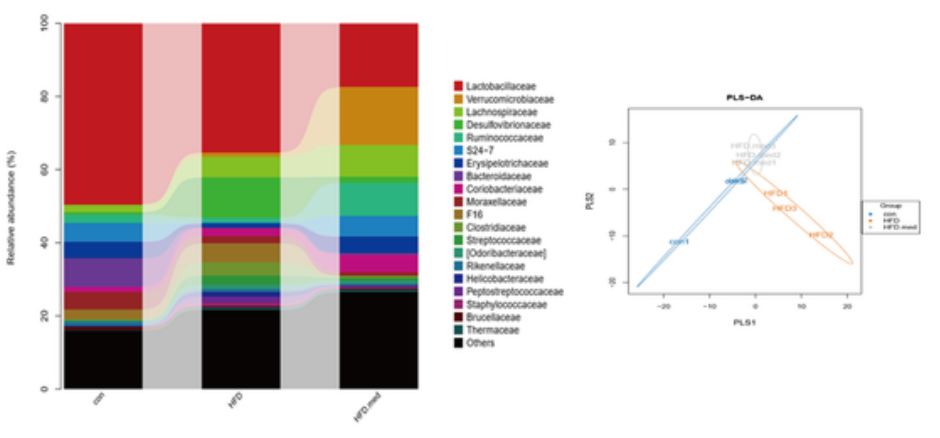

B
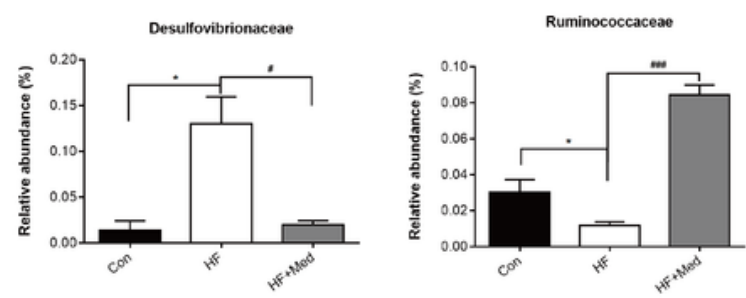

C

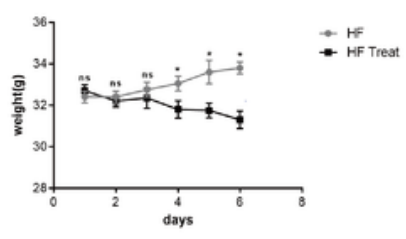

D
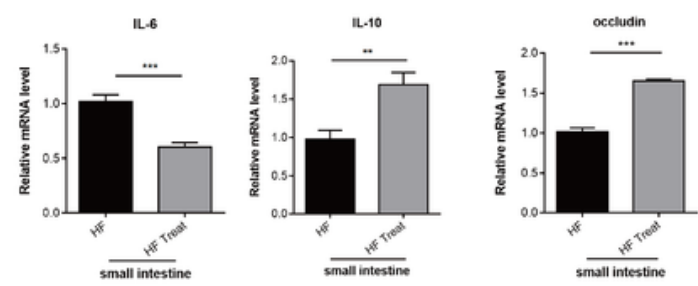

E
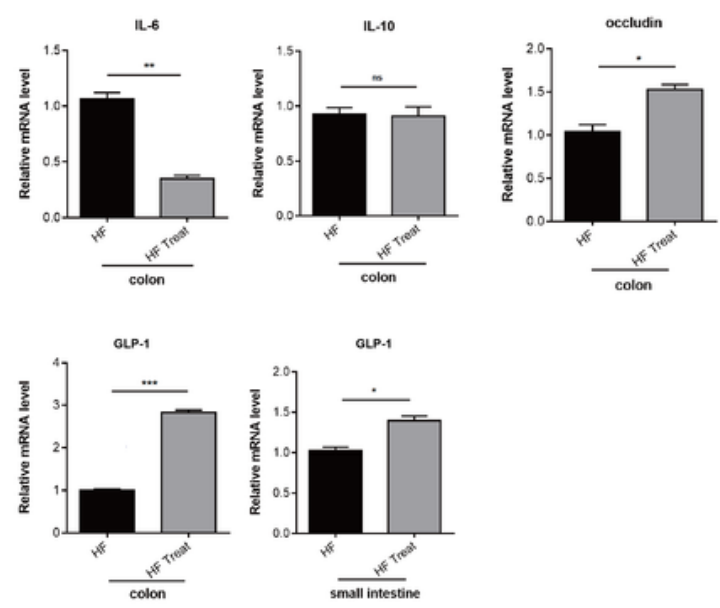

\section{Figure 5}

The drug would alter the microbial environment to that of normal mice in mice (Fig. 5A). Cluster analysis showed increase in the proportion of desulfovibrionaceae in obese mice. This bacterium was associated with obesity [32], whereas traditional Chinese medicine inhibited its proliferation. At the same time, traditional Chinese medicine formula could promote rumen bacteria breeding in obese mice, in order to reduce the rate of mice with constipation [33] (Fig. 5B), Through the flora recovery of obese mice, it was 
found that the body weight of obese mice in the flora recovery group was partially lower than that in the control group (Fig. 5C), intestinal inflammation decreased to some extent, while anti-inflammatory factors increased in varying degrees, and the expression of intestinal tight junction protein was also partially upregulated in obese mice (Fig. 5D). Compared with the control group, the expression of intestinal GLP-1 in obese mice was also up-regulated to a certain extent (Fig. 5E).

A

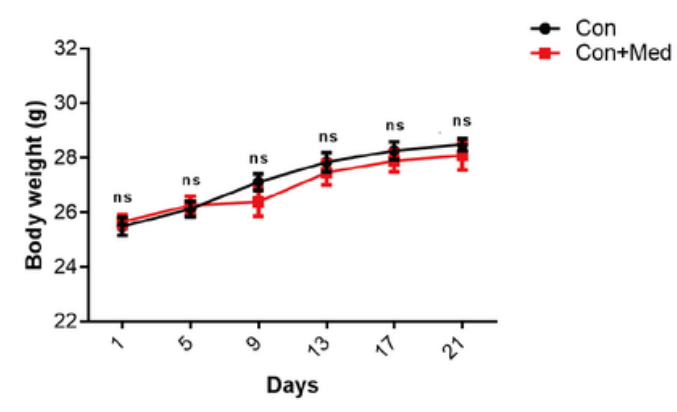

B
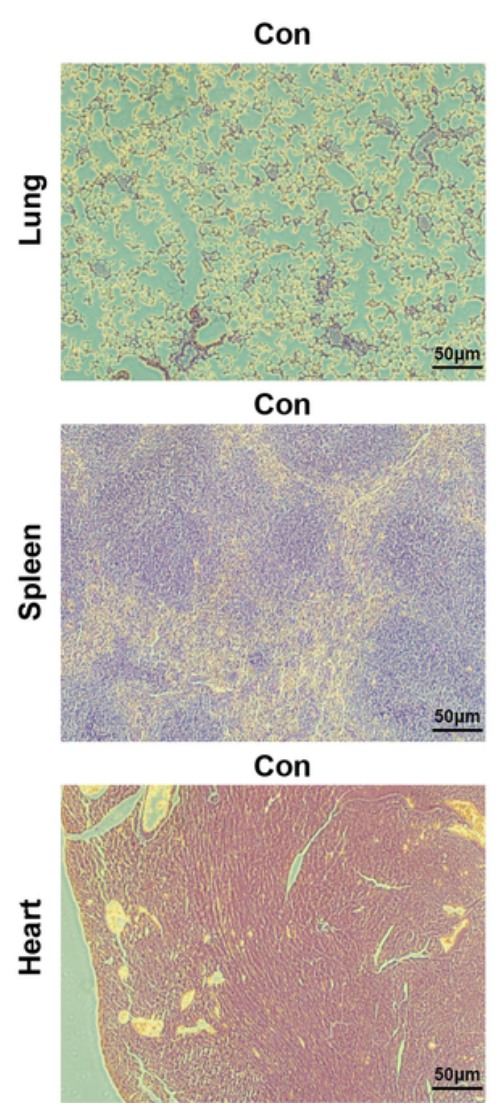

Con+Med

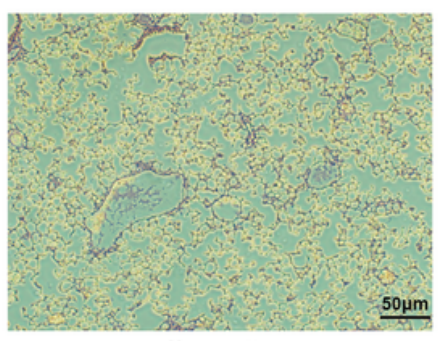

Con+Med

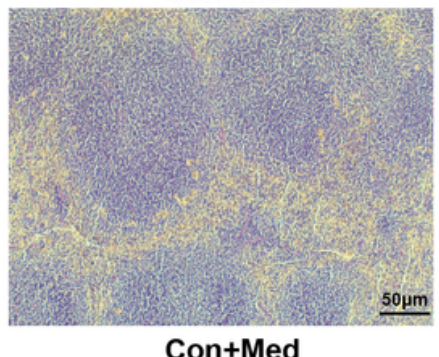

Con+Med

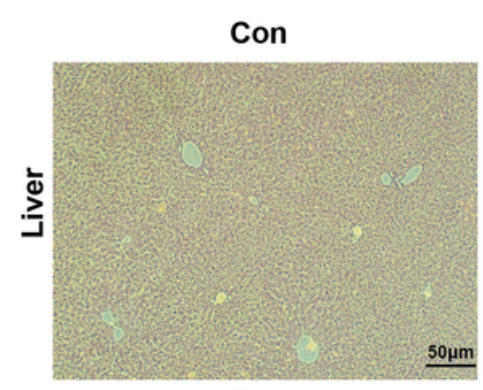

Con

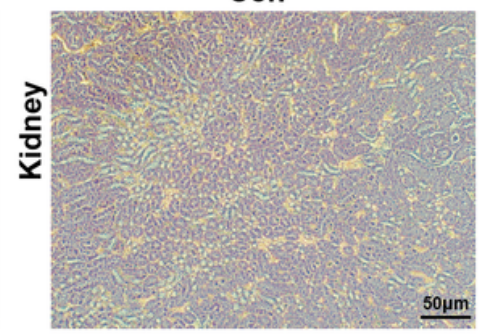

Con+Med

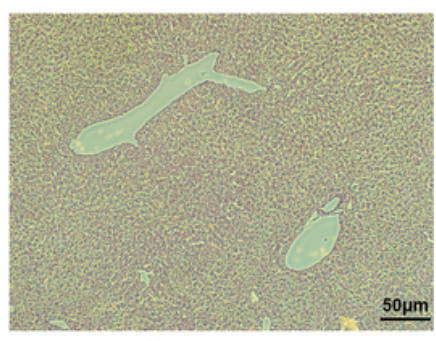

Con+Med

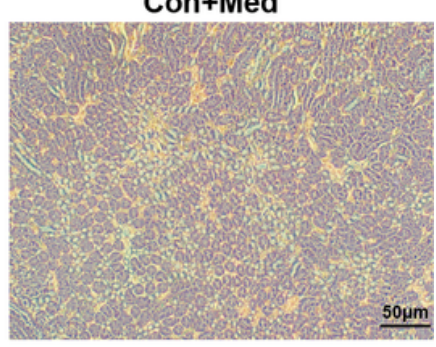

\section{Figure 6}

After obtaining the effective dose of TCM, we explored it's toxicity. As the results showed, TCM had no influence on body weight of mice (Fig.6A). Compare with control, the HE showed that the lungs, the spleens, the hearts, the livers and the kidneys were no focal necrosis, no obvious fibrosis, no destruction of cell structure and no inflammation, there was no obvious difference between the two sets (Fig.6B).

\section{Supplementary Files}


This is a list of supplementary files associated with this preprint. Click to download.

- Figure.S1.png

- supplementarymaterials.docx 